\title{
Raltitrexed Enhances the Antitumor Effect of Apatinib in Human Esophageal Squamous Carcinoma Cells via Akt and Erk Pathways
}

This article was published in the following Dove Press journal: OncoTargets and Therapy

\author{
Hongchao Zhen' \\ Guangxin $\mathrm{Li}^{2}$ \\ Pengfei Zhao' \\ Ying Zhang' \\ Jing Wang' \\ Junxian $\mathrm{Yu}^{3}$ \\ Bangwei Cao'
}

'Cancer Center, Beijing Friendship Hospital, Capital Medical University, Beijing 100050, People's Republic of China; ${ }^{2}$ Radiation Oncology, Beijing Tsinghua Changgung Hospital, School of Clinical Medicine, Tsinghua University, Beijing 1022/8, People's Republic of China; ${ }^{3}$ Department of Pharmacy, Beijing Friendship Hospital, Capital Medical University, Beijing 100050, People's Republic of China
Correspondence: Bangwei Cao Cancer Center, Beijing Friendship Hospital, Capital Medical University, \#95 Yong an Road, Xicheng District, Beijing 100050, People's Republic of China $\mathrm{Tel} / \mathrm{Fax}+86-10-63139325$

Email oncology@ccmu.edu.cn
Objective: Apatinib has been proved effective in the treatment of advanced gastric cancer and a variety of solid tumors. Raltitrexed is emerging as a promising alternative for treating advanced colorectal cancer in China. This work aims to study the combinatory antitumor effect of apatinib and raltitrexed on human esophageal squamous carcinoma cells (ESCC).

Materials and Methods: Two VEGFR-2-positive human ESCC lines, KYSE-30 and TE-1, were treated with apatinib or raltitrexed, or both, then the cell proliferation rate was measured by MTS assay; cell migration and invasion were studied by transwell assays; cell apoptosis rate was determined by flow cytometry; cellular autophagy level affected was analyzed by Western blot analysis; finally, quantitative polymerase chain reaction (qPCR) was used to monitor transcription and Western blot was performed to check phosphorylation of apoptotic proteins after treatment. Results: Both apatinib and raltitrexed significantly inhibited KYSE-30 and TE-1 cell proliferation in a dose-dependent manner. Treatment with both drugs showed enhanced inhibitory effects on cell proliferation, migration, and invasiveness compared with apatinib monotherapy. Apoptosis percentages in both cell lines were also remarkably increased by the combined treatment. Moreover, the combination of apatinib and raltitrexed down-regulated mRNA level of the anti-apoptotic protein Bcl-2, while up-regulated pro-apoptotic protein PARP, Bax, and caspase-3 transcription. Western blot analysis showed that phosphorylation levels of Erk, Akt, and invasiveness-associated protein matrix metalloproteinases-9 (MMP-9) were decreased in the combination group.

Conclusion: Taken together, these results indicate that raltitrexed enhances the antitumor effects of apatinib on human ESCC cells by down-regulating phosphorylation of Akt and Erk, implying a combination of raltitrexed and apatinib might be an effective option for treating esophageal squamous cell carcinoma patients.

Keywords: raltitrexed, apatinib, antitumor, ESCC, Akt, Erk

\section{Introduction}

Esophageal cancer (EC) is one of the most diagnosed malignant tumors of the digestive system globally. Esophageal squamous cell carcinoma (ESCC) accounts for more than $90 \%$ of the pathological types of EC in China. ${ }^{1}$ By now, cisplatinbased and fluorouracil-based systemic chemotherapy reagents are dominant treatments for ESCC; however, the prognosis of ESCC remains poor. Most patients die within 1 year after diagnosis, and the 5-year survival rate is only $8-20 \% .^{2}$ In addition, the toxic side-effects of systemic chemotherapy may further affect the patients' life quality. Therefore, developing an individualized target therapy model will provide promising therapeutic options in treating ESCC patients. 
Angiogenesis plays an important role in the development of tumors. Mechanistically, vascular endothelial growth factor (VEGF) binds to the vascular endothelial growth factor receptor (VEGF-R) which located in the vascular endothelial cells and stimulates the proliferation of vascular endothelial cells by activating the downstream pathways, then leading to the growth of malignant tumor cells. ${ }^{3,4}$ Therefore, blocking the VEGF/VEGFR pathway is a potential therapeutic target for ESCC due to its high expression of VEGF/VEGFR levels. ${ }^{5}$

Apatinib (YN968D1) is a small molecule tyrosine kinase inhibitor that selectively targets the intracellular ATP-binding site of VEGFR-2, and blocks the signal transduction downstream of the VEGF/VEGFR pathway and angiogenesis. ${ }^{6}$ In China, apatinib has been shown to be effective for treating patients with chemotherapyrefractory advanced or metastatic gastric cancers. As reported previously, the median overall survival (OS) and median progression-free survival (PFS) of the apatinib group were prolonged by 1.8 months and 0.8 months, respectively, compared with the placebo group. ${ }^{7}$ Furthermore, many clinical studies have shown that apatinib is also effective in other solid tumors including nonsmall-cell lung cancer (NSCLC), ${ }^{8}$ breast cancer, ${ }^{9}$ and sarcoma. ${ }^{10}$

Raltitrexed (ZD1694), a folate analog, is a specific and a long-acting anti-thymidylate synthase (TS) drug. ${ }^{11}$ Raltitrexed is approved to be effective in patients with metastatic colorectal cancer, especially suitable for patients who cannot tolerate 5-FU and folinic acid-based regimens. In particular, raltitrexed appears to be a better choice for patients with basic cardiovascular diseases. ${ }^{12}$ Meanwhile, because of its direct anti-proliferation and anti-apoptosis effects, raltitrexed has been shown to have antitumor effects on a variety of tumors, including head and neck cancer, malignant mesothelioma, gastric carcinoma, hepatic cancer, and pancreatic carcinoma. ${ }^{13-17}$

Previous studies have confirmed that apatinib and raltitrexed can enhance the radiosensitivity of the esophageal squamous carcinoma cells. ${ }^{18,19}$ In the current study, we attempted to investigate the combined antitumor effects of apatinib and raltitrexed in treating human ESCC and further explored the possible mechanisms. The cellular autophagy affected by apatinib and raltitrexed was also studied. Our work demonstrated that raltitrexed obviously enhances the inhibitory effect of apatinib in KYSE-30 and TE-1 cells by interfering with cell proliferation, motility, and invasion, as well as apoptosis, implicating clinical efficacy of combinatory application of raltitrexed and apatinib in treating human ESCC. Furthermore, our data indicate the combinatory effects of apatinib and raltitrexed are achieved by altering transcription of apoptosis-associated proteins and phosphorylation levels of Erk and Akt. Therefore, our work is meaningful for clinical treatment decisions in the future.

\section{Materials and Methods \\ Cell Culture and Reagents}

HUVEC (human umbilical vein endothelial cell) was purchased from ScienCell Research Laboratories, Inc. (San Diego, CA, USA). Human esophageal squamous carcinoma cell lines KYSE-30 and TE-1 were purchased from the Cell Bank of Type Culture Collection of Chinese Academy of Sciences (Shanghai, China). KYSE-30, TE1, and HUVEC were cultured in Roswell Park Memorial Institute (RPMI)-1640 (Hyclone, Termo Scientific, MA) containing 10\% fetal bovine serum (FBS), $100 \mathrm{U} / \mathrm{mL}$ penicillin, and $100 \mathrm{mg} / \mathrm{L}$ streptomycin (Hyclone, Termo Scientific, MA) in a humidified atmosphere of $5 \% \mathrm{CO}_{2}$ at $37^{\circ} \mathrm{C}$. Apatinib was a gift from Jiangsu Hengrui medicine Co, Ltd (Jiangsu, China). Raltitrexed was purchased from Jiangsu Zhengda Tianqing Pharmaceutical Co., Ltd. (Nanjing, China). Apatinib and raltitrexed were dissolved in dimethyl sulfoxide (DMSO, Solarbio, D8370), and both were prepared freshly prior to use.

\section{Cell Proliferation Assay}

MTS assay was used to detect the cell proliferation in different times according to the protocols. Cells were seeded into 96 -well plates at a density of $5 \times 10^{3}$ cells per well, and incubated for 24 hours at $37^{\circ} \mathrm{C}$. Subsequently, RPMI-1640 containing different concentrations of apatinib or raltitrexed were added into each well and further incubated for 24,48 , or 72 hours according to the experimental design. Cells were incubated with raltitrexed in concentrations ranging from $0-5 \mu \mathrm{M}$ and apatinib ranging from 0 $100 \mu \mathrm{M}$, respectively. MTS solution (10 $\mu \mathrm{L} /$ well) was added to each experimental well and further incubated for an additional 1 hour in humidified conditions at $37^{\circ} \mathrm{C}$. The optical density was measured at a wavelength of $490 \mathrm{~nm}$ according to the indicated time point. The A490 was measured and the proliferation rate was calculated [cell proliferation rate $(\%)=\mathrm{OD} 490 \mathrm{~nm}$ experimental group/OD $490 \mathrm{~nm}$ control group $\times 100 \%$ ] to evaluate the 
proliferation capacity of cancer cells. Each experiment was repeated at least three times independently.

\section{Colony Formation Assay}

The indicated cells were plated evenly in a six-well plate at a density of 1,000 cells per well and incubated for 24 hours. The cells were then treated with different reagents (RPMI-1640, $50 \mu \mathrm{M}$ apatinib, $2.5 \mu \mathrm{M}$ raltitrexed, or 50 $\mu \mathrm{M}$ apatinib plus $2.5 \mu \mathrm{M}$ raltitrexed) for approximately 14 days. The foci were stained by $0.05 \%$ crystal violet and counted with an ordinary optical microscope.

\section{Transwell Invasion Assay}

The transwell assay by the $8-\mu \mathrm{m}$ chamber (BD, Bedford, MA) was carried out to detect the cell migration and invasion ability. Firstly, pre-chilled upper inserts were pretreated with matrigel (Corning, USA) (1:20 in dilution). Then upper inserts were hydrated by RPMI-1640 without FBS for 1 hour at room temperature before KYSE-30 and TE-1 cells were sowed into the upper chamber. Subsequently, KYSE-30 $\left(1 \times 10^{5} /\right.$ well $)$ and TE- $1\left(1 \times 10^{5} /\right.$ well) cells with serum-free RPMI-1640 medium suspension containing different reagents were added to the upper chamber and the culture medium supplemented with $10 \%$ FBS was added to the lower chamber. The concentration of apatinib and raltitrexed was $50 \mu \mathrm{M}$ and $2.5 \mu \mathrm{M}$, separately. After incubating for 24 hours in a $5 \% \mathrm{CO}_{2}$ atmosphere at $37^{\circ} \mathrm{C}$, the cells at the upper layer were removed carefully using a cotton swab, while the invaded cells left at the bottom of the chambers were fixed in $4 \%$ paraformaldehyde for 30 minutes and stained with $0.5 \%$ crystal violet solutions for 10 minutes at room temperature. Finally, the crystal violet-positive cells for each chamber were counted in six random visual fields under an inverted phase contrast microscope (Olympus, Japan), and the average number of invaded cells per view field was calculated.

\section{Apoptosis Assay}

KYSE-30 and TE- 1 cells were plated and grown in sixwell plates overnight before they were incubated with different reagents for 48 hours. Then cells were divided into four groups: control, apatinib $(50 \mu \mathrm{M})$, raltitrexed $(2.5 \mu \mathrm{M})$, and apatinib + raltitrexed $(50 \mu \mathrm{M}+2.5 \mu \mathrm{M})$. Annexin V-FITC and propidium iodide (PI) staining assays were employed to determine the cell apoptosis, and an apoptosis detecting kit (KeyGen, Nanjing, China) was used following the manufacturer's instruction. And then cells were harvested in EDTA-free trypsin solution and washed twice with pre-chilled PBS by centrifugating for 5 minutes at $2,000 \mathrm{rpm} /$ min. Then the cell pellets were resuspended in 300 $\mu \mathrm{L}$ binding buffer and incubated with $5 \mu \mathrm{L}$ Annexin V-FITC on ice in the dark for 15 minutes, followed by addition of $5 \mu \mathrm{L}$ PI solution to each group. The apoptosis rate in each group was determined by flow cytometry (FCM, BD FACS Calibur) and described by Q2 (late apoptosis) + Q4 (early apoptosis). All experiments were repeated three times.

\section{Quantitative Polymerase Chain Reaction (qPCR) Analysis}

The cellular total RNA was extracted using a PARISTM Kit (Applied Biosystems, MA, USA) and reverse transcription was carried using MultiscribeTM Reverse Transcriptase (Applied Biosystems, MA, USA). The samples were homogenized with TRIzol Reagent, mixed vigorously for about 30 seconds with $200 \mu \mathrm{L}$ chloroform, and kept at room temperature for 3-5 minutes, then centrifuged at $1.4 \times 10^{4} \mathrm{rpm}$ at $4^{\circ} \mathrm{C}$ for 15 minutes. After transferring the supernatant to a new RNase-free EP tube, the supernatant was precipitated with the same volume of isopropanol for 10 minutes at room temperature and centrifuged at $1.2 \times 10^{4} \mathrm{rpm}$ for 10 minutes. The RNA sediments were washed with $75 \%$ ethanol twice, air-dried, and dissolved in $100-200 \mu \mathrm{L}$ of nuclease-free water. One microgram of total RNA was reverse transcribed into first strand cDNA with oligo (dT) primers in the presence of a reverse transcriptase. PCR amplification was performed with a total volume of $50 \mu \mathrm{L}$ containing $1 \mu \mathrm{L}$ of the first strand cDNA synthesis reaction mixture. qPCR was performed in triplicate in a $20 \mu \mathrm{L}$ reaction mixture containing $10 \mathrm{ng}$ cDNA, 0.5 $\mu \mathrm{M}$ of each primer, and $10 \mu \mathrm{L}$ of SYBR Premix Ex Taq Master Mix (2×) (Takara). The expression level was calculated by the comparative $\mathrm{Ct}$ method. The primers used in this research are listed in Table 1.

\section{Western Blot Analysis}

KYSE-30 and TE-1 cells were treated with indicated concentrations of reagents after 48 hours incubation in $6 \mathrm{~cm}^{2}$ plates. Then cells were lysed in radioimmunoprecipitation assay buffer (RIPA) (Applygen, Beijing, China) supplemented with protease inhibitor cocktail (Amresco, $\mathrm{OH}, \mathrm{USA}$ ). The supernatants were collected by centrifugating at $12,000 \times \mathrm{g}$ at $4^{\circ} \mathrm{C}$ for 15 minutes, and protein 
Table I The Primers Used in This Work

\begin{tabular}{|l|l|}
\hline Targets & Primer Sequence (5'-3') \\
\hline PARP & $\begin{array}{l}\text { Forward: 5'-CCCCACGACTTTGGGATGAA-3' } \\
\text { Reverse: 5'-AGACTGTAGGCCACCTCGAT-3' }\end{array}$ \\
\hline Bax & $\begin{array}{l}\text { Forward: 5'-TGAAGCGACTGATGTCCCTG-3' } \\
\text { Reverse: 5'-CAAAGATGGTCACGGTCTGC-3' }\end{array}$ \\
\hline Caspase-3 & $\begin{array}{l}\text { Forward: 5'-CCTGGTTCATCCAGTCGCTT-3' } \\
\text { Reverse: 5'-TCTGTTGCCACCTTTCGGTT-3' }\end{array}$ \\
\hline Bcl-2 & $\begin{array}{l}\text { Forward: 5'-GTGAAGTCAACATGCCTGCC-3' } \\
\text { Reverse: 5'-ACAGCCTGCAGCTTTGTTTC-3' }\end{array}$ \\
\hline
\end{tabular}

concentration was quantified using a BCA protein assay kit (Merck, Darmstadt, Germany). For Western blot, 30 $\mu \mathrm{g}$ proteins were separated in $10 \%$ SDS polyacrylamide gels and transferred to NC membranes. After blocking with $5 \%$ fat-free milk in TBST buffer $(0.1 \%$ Tween- 20$)$ for 40 minutes at room temperature, they were incubated with primary antibodies, VEGFR2 (1:1,000, Cell Signaling Technology), p-VEGFR2 (1:1,000, Cell Signaling Technology), Caspase-3 $\quad(1: 1,000$, Cell Signaling Technology), p-Caspase-3 (1:1,000, Cell Signaling Technology), MMP9 (1:1,000, Abcam), Bax (1:1,000, Cell Signaling Technology), Bcl-2 (1:1,000, Cell Signaling Technology), ERK (1:1,000, Cell Signaling Technology), p-ERK (1:1,000, Cell Signaling Technology), AKT (1:1,000, Cell Signaling Technology), p-AKT $(1: 1,000$, Cell Signaling Technology), LC3 (1:1,000, Cell Signaling Technology), and $\beta$-ACTIN (1:1,000, Cell Signaling Technology), at $4^{\circ} \mathrm{C}$ overnight. The membranes were then washed using TBST buffer and incubated with HRP-conjugated secondary antibody (1:5,000, Cell Signaling Technology) at RT for $40 \mathrm{~min}-$ utes. Finally, the protein bands were detected using chemiluminescence (Millipore) and exposed to X-ray films.

\section{Statistical Analysis}

The data in this study were presented as mean \pm standard deviation from at least three independent experiments and the statistical graphs were generated using GraphPad Prism 5 (GraphPad Software, Inc., La Jolla, CA, USA). One-way analysis of variance (ANOVA) was used to analyze differences between groups and SPSS 19.0 software (IBM Corp., Armonk, NY, USA) was used to evaluate the statistical differences. $P<0.05$ indicates a statistically significant difference.

\section{Results}

\section{Raltitrexed Enhances the Inhibitory Effects of Apatinib on Cell Proliferation and Viability}

Plenty of chemotherapy reagents have been developed for treatment of tumors, among which esophageal squamous cell carcinoma (ESCC) is one of the most malignant with poor diagnosis. Whether a combination of apatinib and raltitrexed can generate a better therapeutic effect is an interesting question but has been rarely reported. To address this issue, we carried out studies to compare the combinatory antitumor effects of apatinib and raltitrexed to that of monotreatment using ESCC cell lines. Firstly, we selected two ESCC cell lines, KYSE-30 and TE-1, which expressed the vascular endothelial growth factor receptor, VEGFR-2. ${ }^{20,21}$ As shown in Figure 1A, Western blot result indicated that VEGFR-2 was detected in both KYSE-30 and TE-1 cells, with the HUVEC cell line used as the positive control for VEGFR-2 expression.

Next, we examined how apatinib and raltitrexed treatments change the proliferation capacity of KYSE-30 and TE-1 cells. We incubated each cell line with different concentrations of apatinib or raltitrexed or both on a 96well plate, and we detected proliferation of these cells by MTS assay. As shown in Figure 1B, apatinib treatment on KYSE- 30 cells at a concentrations of $10 \mu \mathrm{M}, 30 \mu \mathrm{M}$, and $50 \mu \mathrm{M}$ decreased the cell proliferation rate and it became significantly different from the control group after 72 hours incubation; when incubating with $100 \mu \mathrm{M}$ apatinib, the reduction appeared to be significant much earlier (after 24 hours of incubation). Similarly, when incubated with raltitrexed at concentrations of $1 \mu \mathrm{M}, 2 \mu \mathrm{M}$, and $2.5 \mu \mathrm{M}$, a significant reduction effect appeared after incubating 48 hours in comparison to the control, while treatment with 5 $\mu \mathrm{M}$ raltitrexed reacted earlier at 24 hours incubation. These data indicate both apatinib and raltitrexed bear strong anti-proliferation effects in a concentration dependent manner. Based on the above results as well as previous data from our research group, ${ }^{22-24}$ we chose $50 \mu \mathrm{M}$ apatinib and $2.5 \mu \mathrm{M}$ raltitrexed to treat KYSE-30 cells and checked if any combinatory effect existed. It appeared that in comparison to the mono-treatment with apatinib or raltitrexed, the cell proliferation rate decreased much more after incubation with both reagents for 48 hours, reflecting an obvious combinatory effect on cell proliferation for apatinib and raltitrexed. Exactly similar effects were gained for the same treatment on TE-1 cells (Figure 1C). 
A

HUVEC KYSE-30 TE-1

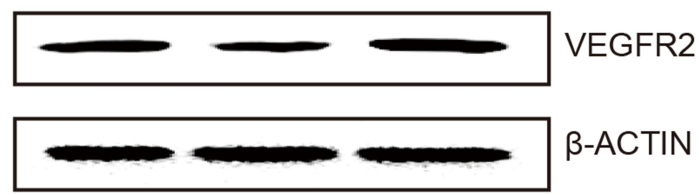

B
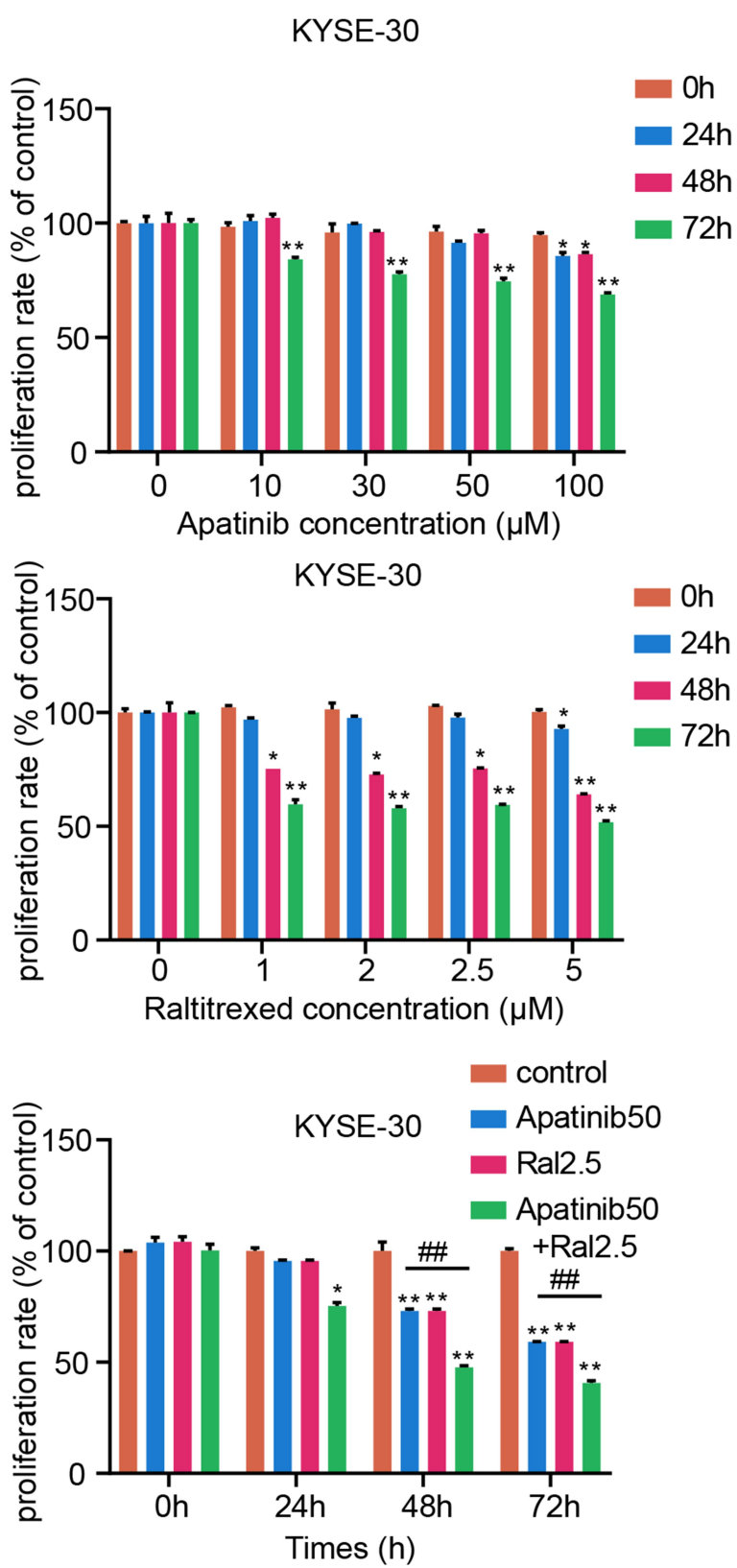

C
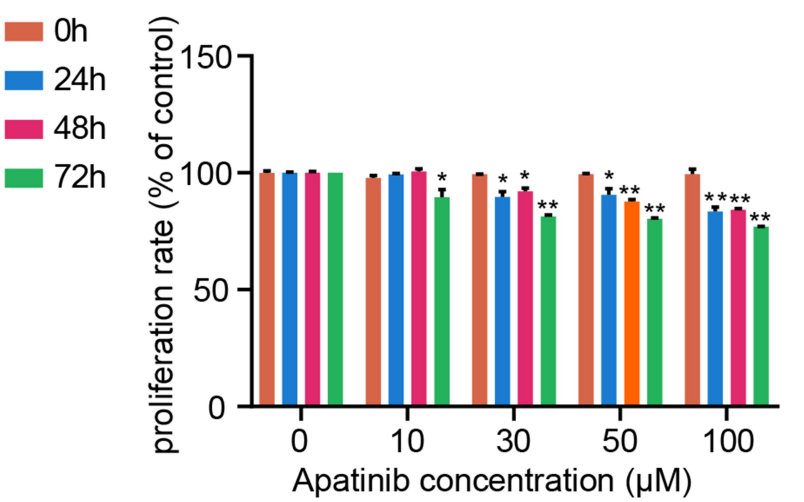

Oh

- $24 \mathrm{~h}$

- $48 \mathrm{~h}$

$72 \mathrm{~h}$
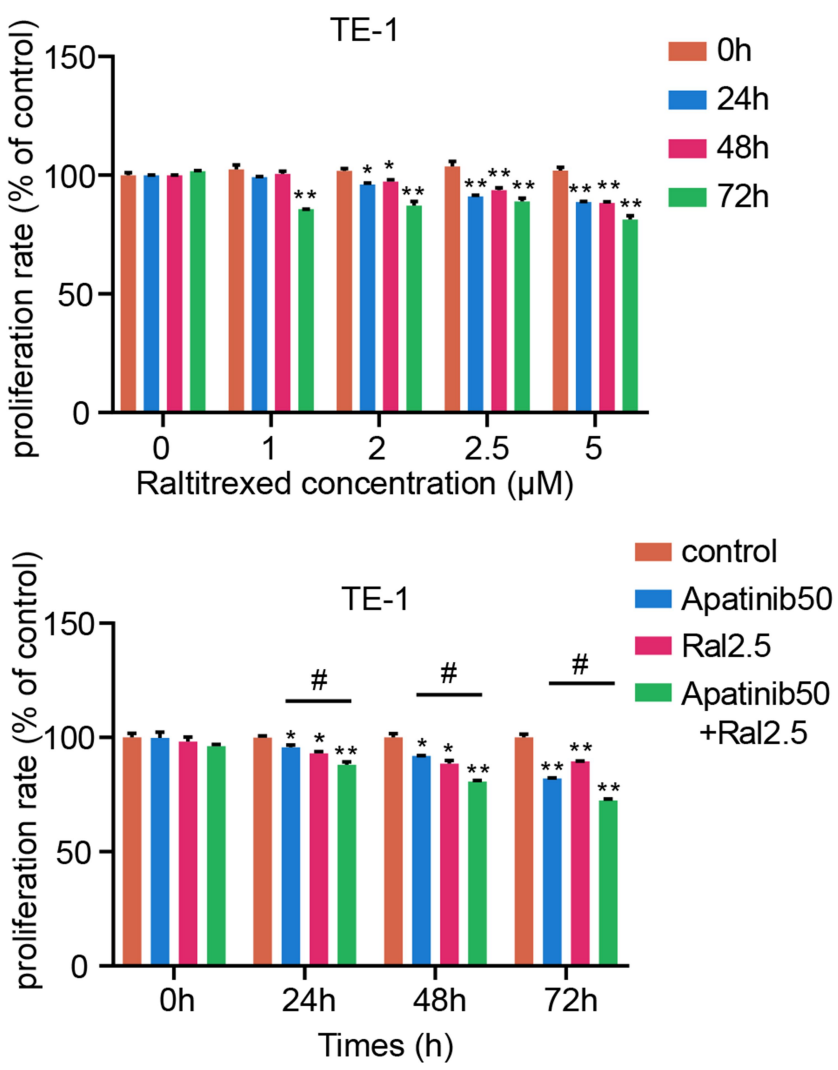

Figure I Combined effects of raltitrexed and apatinib on cell proliferation in ESCC cells. (A) Detection of VEGFR2 expression in KYSE30 and TE-I cells by Western blot. $\beta$ ACTIN was detected as loading control. (B and C) Cell proliferation rates of KYSE-30 (B) and TE-I (C) cells after being treated with control, $50 \mu M$ apatinib, $2.5 \mu M$ raltitrexed, or $50 \mu \mathrm{M}$ apatinib $+2.5 \mu \mathrm{M}$ raltitrexed for the indicated time in MTS assays. Data indicate means $+ \pm S D$ of three biological replicates. Student's $t$-test; $* P<0.05$, ${ }^{* *} P<0.0$ l (vs control); ${ }^{\#} P<0.05,{ }^{\#} P<0.01$ (vs $50 \mu M$ apatinib). 
Then a colony formation assay was carried out to further validate the anti-proliferative effect of raltitrexed and apatinib on human ESCC cells. Based on the results in Figure 1, we chose $50 \mu \mathrm{M}$ apatinib combined with $2.5 \mu \mathrm{M}$ raltitrexed to treat each cell line and incubated for 14 days. We observed from the colony staining pictures that the number of stained colonies decreased drastically in the apatinib or raltitrexed monotherapy group compared with the control group in KYSE-30 (Figure 2A) and TE-1 (Figure 2C) cells, and the cell colonies became almost invisible in the combination group. Quantification results of colony numbers also indicated that all the three treatments significantly inhibited colony formation compared to the control group $(P<0.001)$, and, more importantly, combining raltitrexed with apatinib significantly decreased more colony formation than the monotherapy (Figure $2 \mathrm{~B}$ and $\mathrm{D}$, $P<0.001)$.

Taking these data together, raltitrexed obviously enhanced the inhibitory effects of apatinib on both cell proliferation and viability of ESCC.

\section{Raltitrexed Enhances the Inhibitory Effects of Apatinib on Cell Invasion}

Then transwell assays were performed to determine the effects of apatinib and raltitrexed on cell migration and invasion in KYSE-30 and TE- 1 cells. For the transwell invasion assay, $1 \times 10^{5}$ KYSE- 30 or TE- 1 cells per well were used by resuspending them in the migration buffer supplied with $50 \mu \mathrm{M}$ apatinib, $2.5 \mu \mathrm{M}$ raltitrexed, or both. Cells were photographed after 24 hours of incubation. As shown in Figure 3A (KYSE-30) and 3C (TE-1),

\section{A}

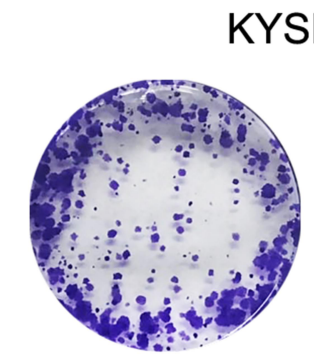

control

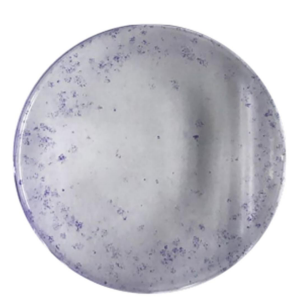

Ral2.5

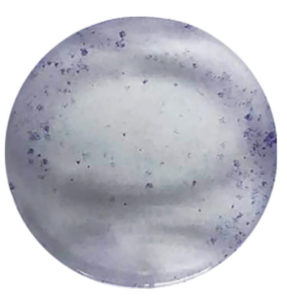

Apatinib50

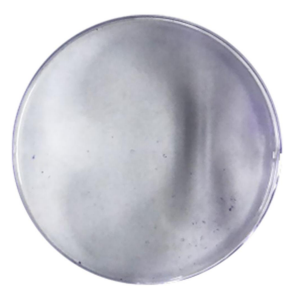

Apatinib50

+Ral2.5

B

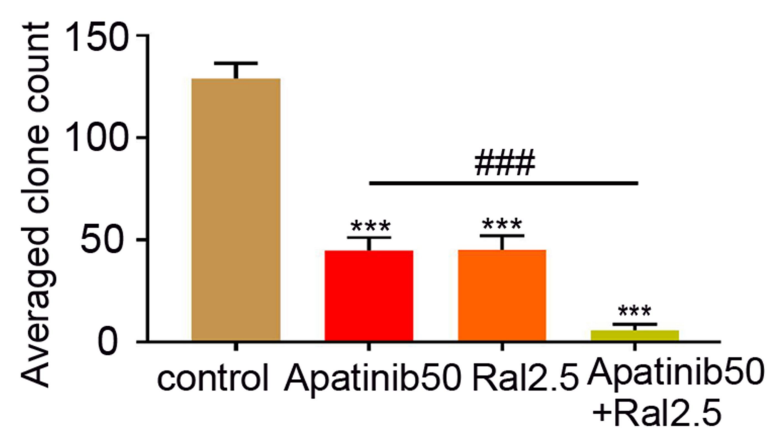

C

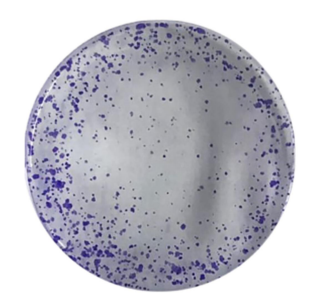

control

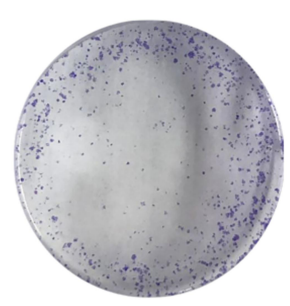

Ral2.5
TE-1

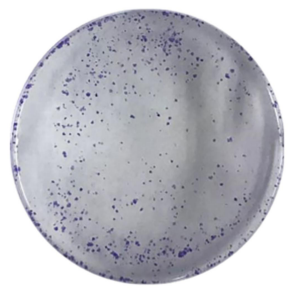

Apatinib50

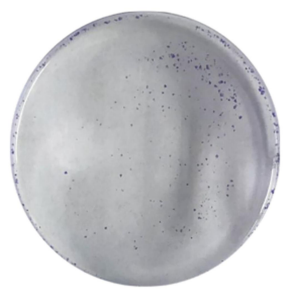

Apatinib50

+Ral2.5

D

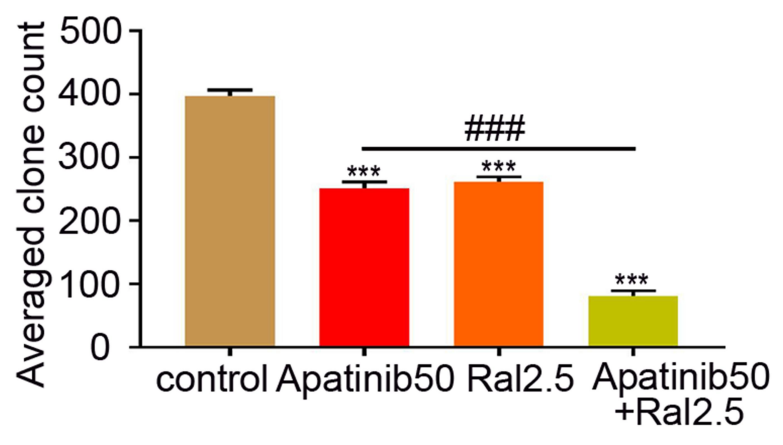

Figure 2 Combined effects of raltitrexed and apatinib on viability of ESCC cells. (A and C) Representative images of colony formation assay after KYSE-30 (A) and TE-I (C) cells were treated with control, $50 \mu \mathrm{M}$ apatinib, $2.5 \mu \mathrm{M}$ raltitrexed, or $50 \mu \mathrm{M}$ apatinib $+2.5 \mu \mathrm{M}$ raltitrexed for 14 days. (B and $\mathbf{D})$ Quantification of the colony formation assays in KYSE-30 (B) and TE-I (D) cells shown in (A and C), respectively. Data indicate means \pm SD of three biological replicates. Student's $t$-test; $* * * P<0.00 I$ (vs control); \# $P$ <.00I (vs $50 \mu \mathrm{M}$ apatinib). 
A
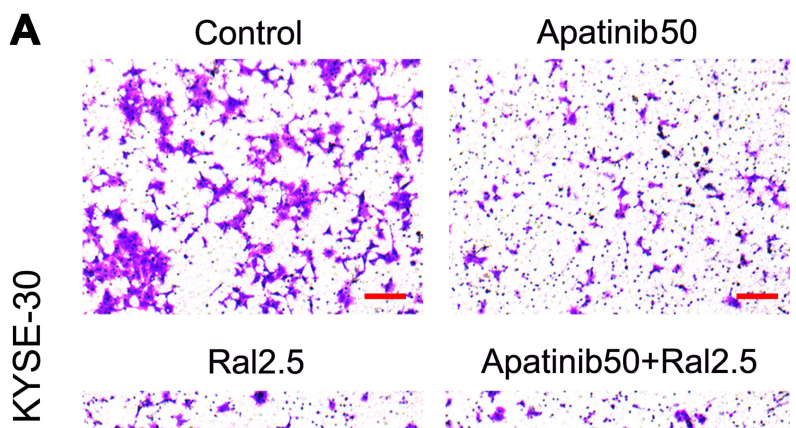

崩

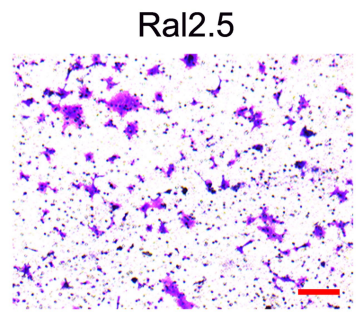

C

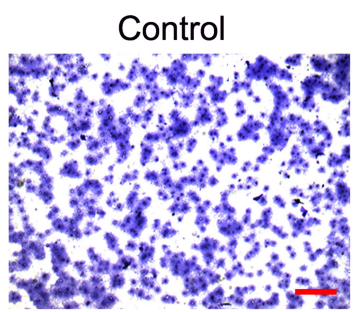

官

Ral2.5

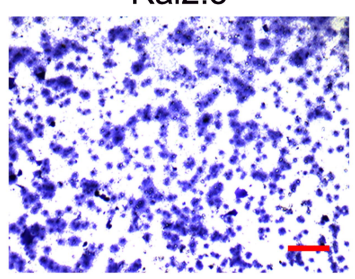

Apatinib50+Ral2.5

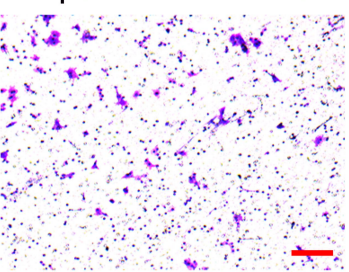

Apatinib50

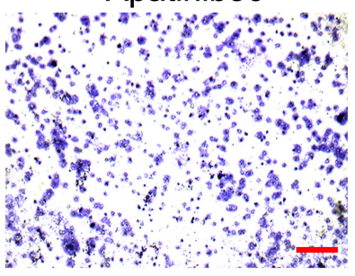

Apatinib50+Ral2.5

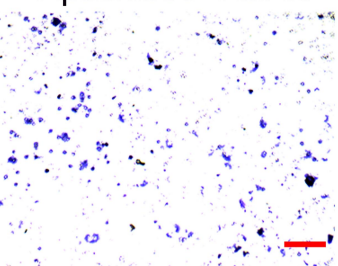

B

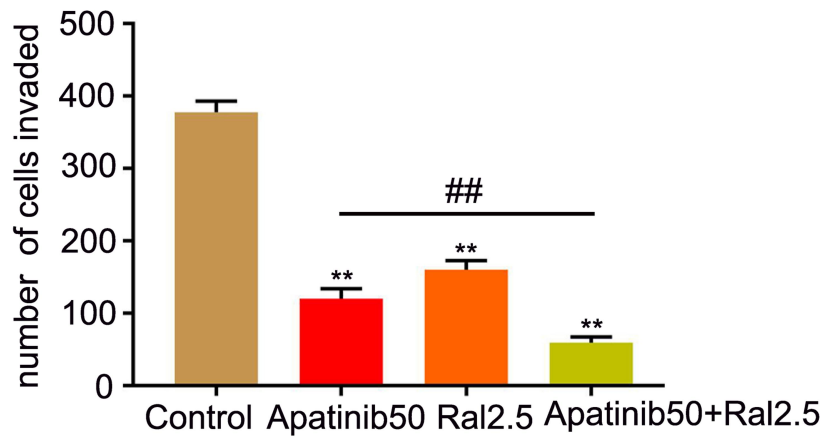

D

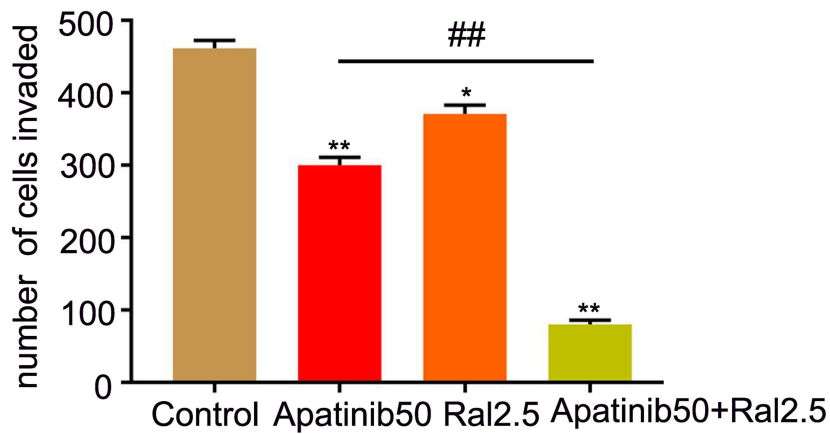

Figure 3 Combined effects of raltitrexed and apatinib on cell invasion in ESCC cells. Transwell analysis of KYSE-30 (A and B) and TE-I (C and D) cells was performed 24 hours after treatment with control, $50 \mu \mathrm{M}$ apatinib, $2.5 \mu \mathrm{M}$ raltitrexed, or $50 \mu \mathrm{M}$ apatinib $+2.5 \mu \mathrm{M}$ raltitrexed. Data indicate means $\pm S D$ of three biological replicates. Student's $t$-test; $* P<0.05,{ }^{*} * P<0.01$ (vs control); ${ }^{\#} P<0.05$, ${ }^{\#} P<0.01$ (vs $50 \mu M$ apatinib). Magnification $\times 100 ;$ Scale bar $=200 \mu \mathrm{m}$.

incubation of each strain with $50 \mu \mathrm{M}$ apatinib was enough to obviously suppress their motility compared to those without any treatment (control); Treatment with $2.5 \mu \mathrm{M}$ raltitrexed could achieve a similar effect in both cells; It is worth noting that the invasion ability of each cell was further reduced by combined treatment of $50 \mu \mathrm{M}$ apatinib and $2.5 \mu \mathrm{M}$ raltitrexed. Meanwhile, quantitative results in Figure 3B (KYSE-30) and Figure 3D (TE-1) also indicated that inhibition difference of each monotherapy was obvious in comparation to the control group, and combinatory treatment further significantly inhibited cell invasion ability (all $P<0.01$ ). Altogether, these results demonstrate that raltitrexed exhibits enhanced activity of apatinib in suppressing ESCC cell migration capacity.

\section{Combinatory Effect of Raltitrexed and Apatinib on Inducing Cell Apoptosis}

We further studied if raltitrexed and apatinib have a similar combinatory effect on inducing cell apoptosis in ESCC. Annexin V and PI staining assay was performed to detect the apoptotic KYSE-30 and TE-1 cells treated in a similar way to that shown in Figure 4, and 48 hours later the apoptosis percentage was analyzed by flow cytometry. In either apatinib or raltitrexed monotherapy group (Figure 4), the apoptosis percentage of KYSE-30 (A and B) and TE-1 (C and D) cells was much higher than the control group $(P<0.05)$, indicating strong induction of apoptosis by each reagent; Notably, the apoptosis rates of the apatinib plus raltitrexed treatment group became obviously higher than each monotherapy group in both KYSE-30 
A

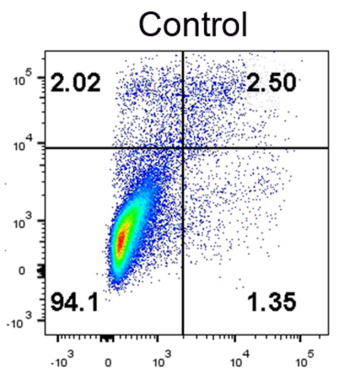

Ral

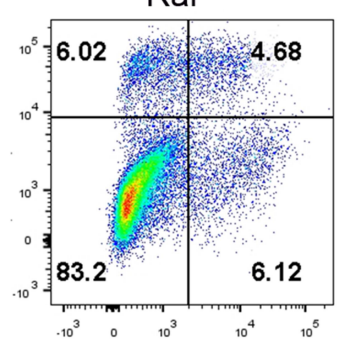

C

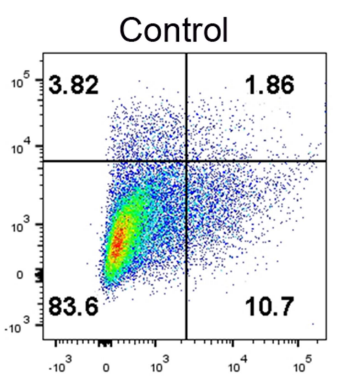

Ral

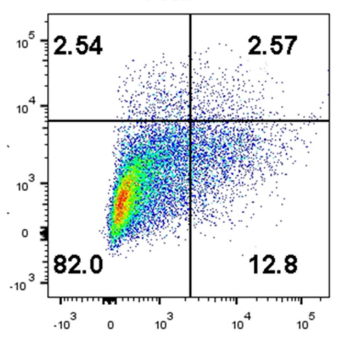

Apatinib

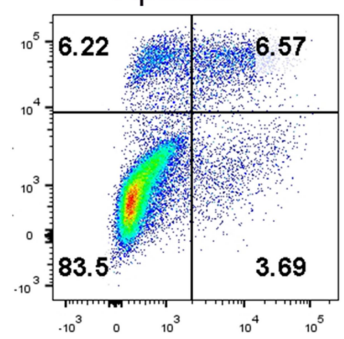

Apatinib+Ral
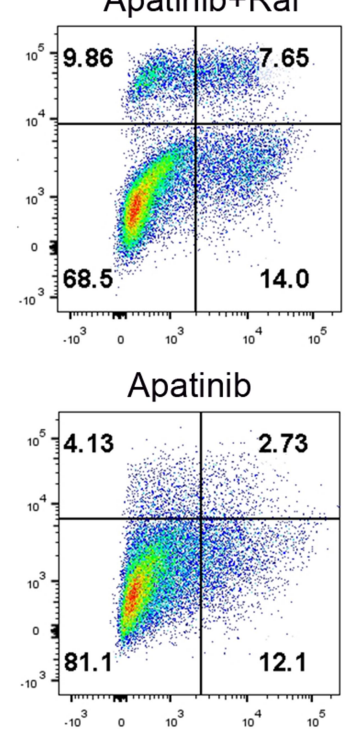

Apatinib+Ral

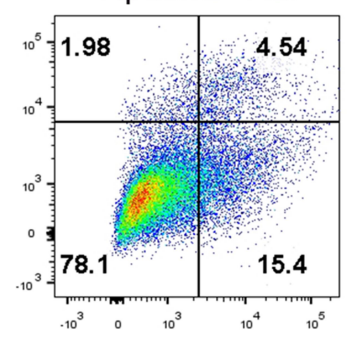

B

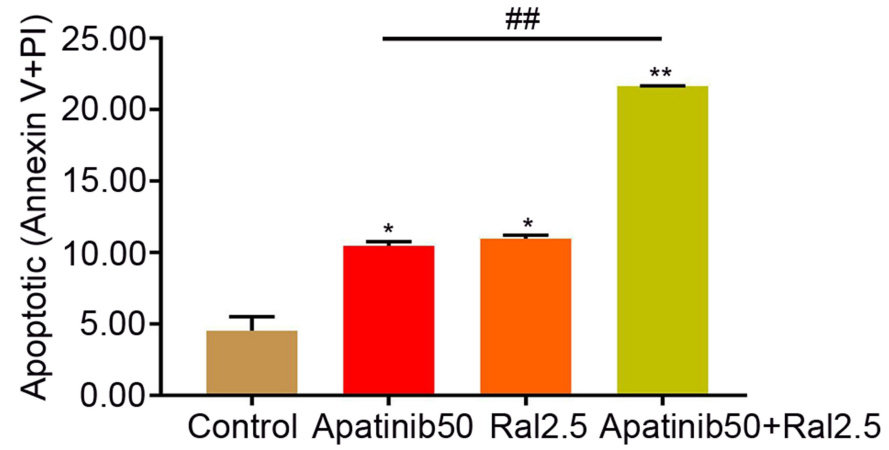

D

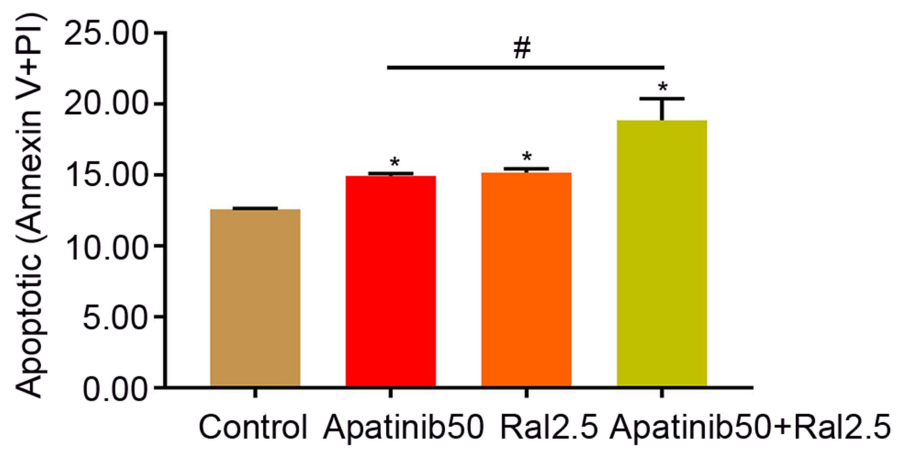

Figure 4 Combined effects of raltitrexed and apatinib on cell apoptosis in ESCC cells. KYSE-30 (A and B) and TE-I (C and D) cells were exposed to control, $50 \mu \mathrm{M}$ apatinib, $2.5 \mu \mathrm{M}$ raltitrexed, or $50 \mu \mathrm{M}$ apatinib $+2.5 \mu \mathrm{M}$ raltitrexed for 48 hours before Annexin V-FITC and PI staining and apoptosis percentage was detected by flow cytometry. Data indicate means $\pm S D$ of three biological replicates. Student's $t$-test; ${ }^{*} P<0.05,{ }^{* *} P<0.01$ (vs control); ${ }^{\#} P<0.05,{ }^{\#} P<0.01$ (vs $50 \mu M$ apatinib).

and TE-1 cells, indicating further induction by the combination.

To confirm the flow cytometry result, the transcriptional level of apoptosis-associated genes was measured by qPCR analysis. As shown in Figure 5, The expression of pro-apoptotic protein mRNA, including PARP, Bax, and caspase-3, was stimulated by both apatinib and raltitrexed monotherapy group compared to the control group, and the elevation became more noticeable in the combination group compared to apatinib monotherapy group in both KYSE-30 (Figure 5A-C) and TE-1 (Figure 5E-G). In contrast, the expression of anti-apoptotic protein (Bcl-2), which had been reported to be an apoptosis regulator, ${ }^{18,25}$ was inhibited in apatinib or raltitrexed monotherapy group in comparation to the control group, and further decreased significantly in the combination group compared to monotherapy group in each cell type (Figure 5D and $\mathrm{H}$ ) (all $P<0.05)$. To further investigate the mechanism underlying the combined effect of raltitrexed and apatinib on promoting apoptosis, the expression of Bax, cleaved caspase-3, and Bcl-2 in both KYSE-30 and TE-1 cells were examined by Western blot analysis. Consistent with the trends of apoptosis rates assayed by flow cytometry, Western blot analysis showed the increased expression of Bax and 
A
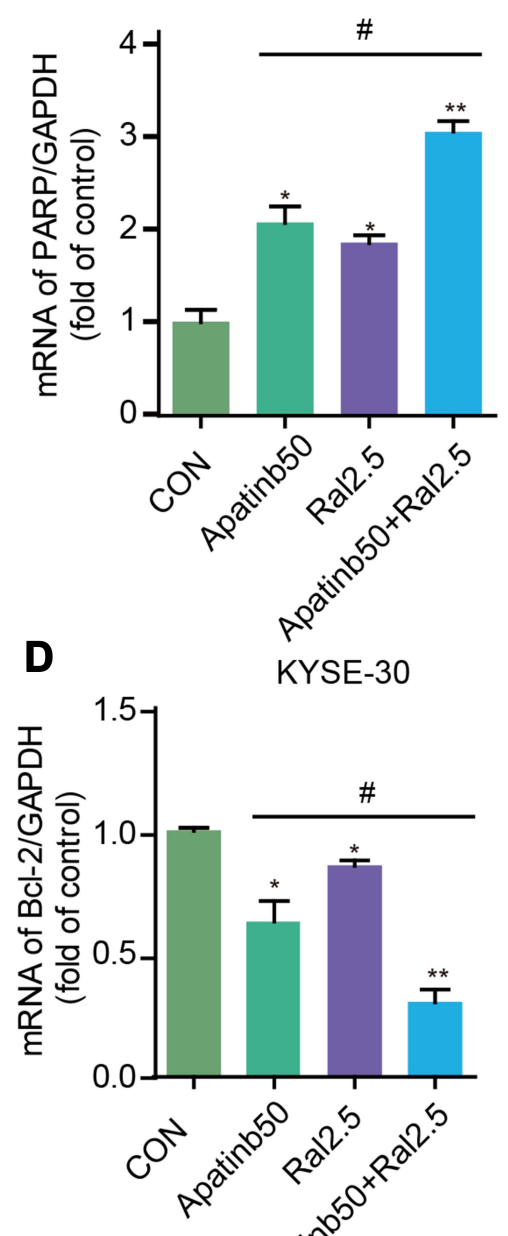

G

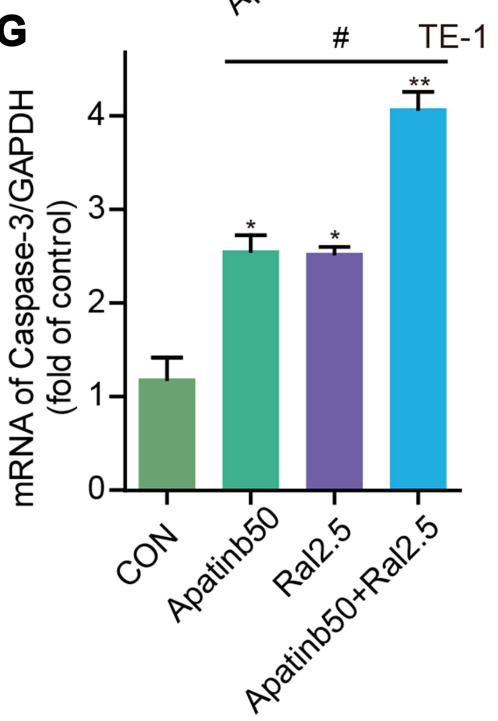

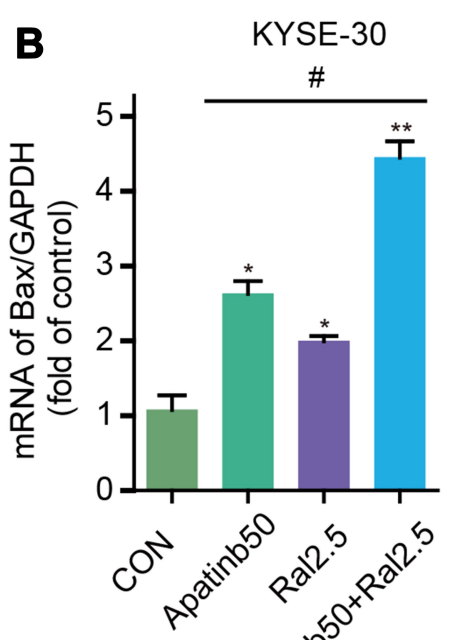

C KYSE-30
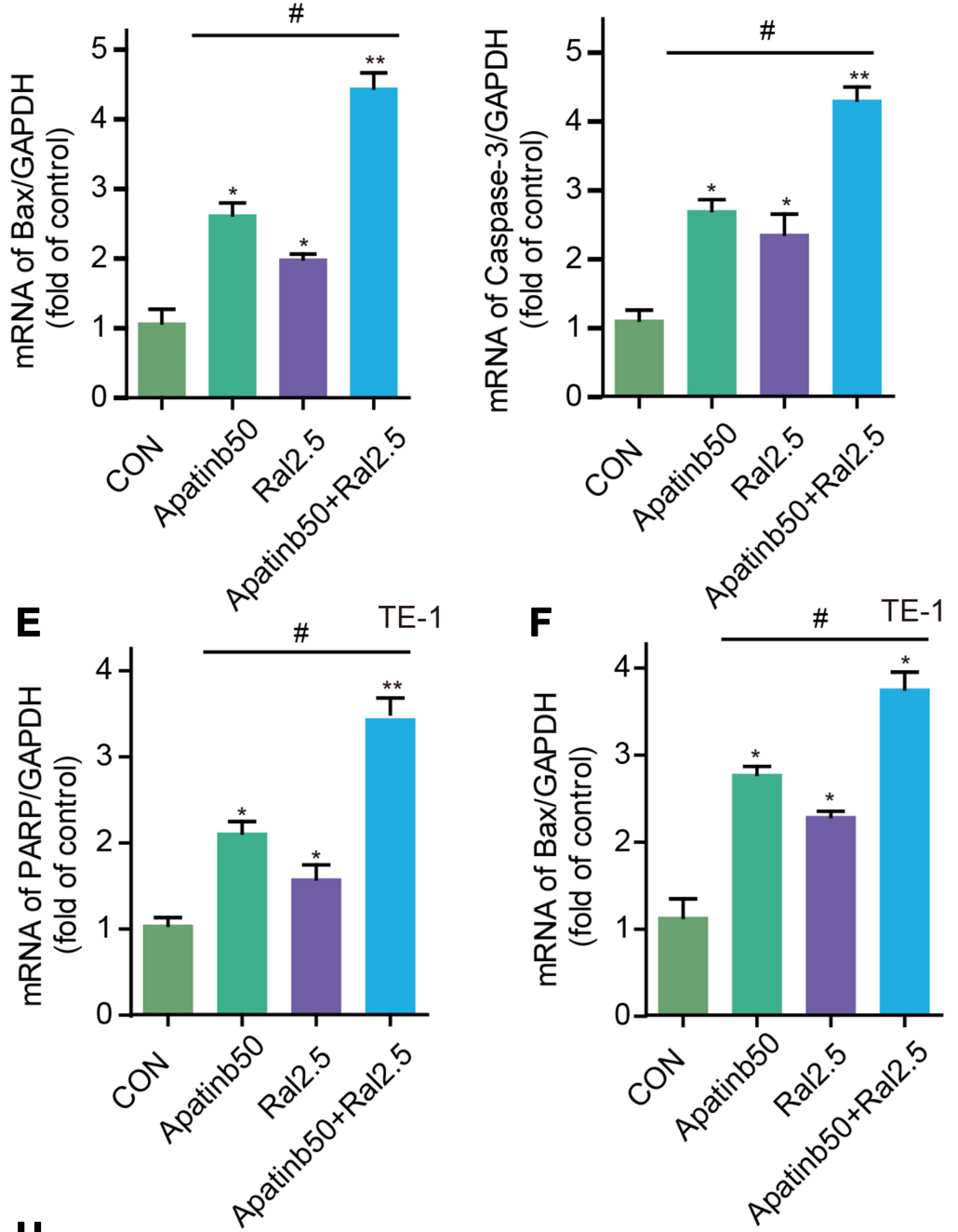

H

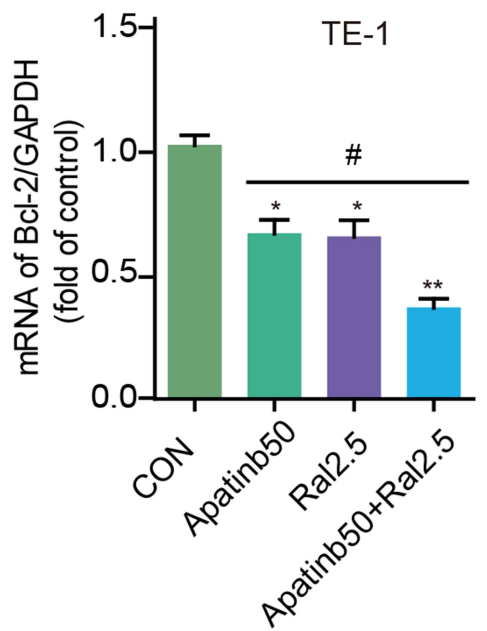

Figure 5 Combined effect of raltitrexed and apatinib on apoptosis-associated gene transcription in ESCC cells. mRNA levels of PARP, Bax, Caspase-3, and Bcl-2 were measured by qPCR in either KYSE-30 (A-D) or TE-I (E-H) cells after treated by $50 \mu \mathrm{M}$ apatinib, $2.5 \mu \mathrm{M}$ raltitrexed, or both. Data indicate means \pm SD of three biological replicates. Student's $t$-test; ${ }^{*} P<0.05,{ }^{*} * P<0.01$ (vs control); ${ }^{\#} P<0.05,{ }^{\#} P<0.01$ (vs $50 \mu M$ apatinib). 
cleaved caspase-3 in apatinib and raltitrexed monotherapy group compared to the control group, and the trends were more evident in the combination group compared to apatinib monotherapy group in both KYSE-30 (Figure 6) and TE-1 (Figure 7) cells (all $P<0.01$ ). Conversely, the expression of Bcl-2 was decreased in each monotherapy group in both KYSE-30 and TE-1 cells $(P<0.01)$, and the down regulation became more significant in the combination group compared to the apatinib monotherapy group in both KYSE-30 (Figure 6) and TE-1 (Figure 7) cells $(P<0.01)$. Taken together, these results support that raltitrexed and apatinib have a combinatory effect on inducing cell apoptosis.

\section{Apatinib Combined with Raltitrexed Up-Regulates the Expression of MMP-9 While Down-Regulates $\mathrm{p}$-Akt and p-Erk}

To help understand the mechanism underlying those antitumor effects described above, Western blot analysis was again carried out to check the dynamic level of several important proteins after KYSE-30 and TE-1 cells were treated with either apatinib, raltitrexed, or both. First, MMP-9, ${ }^{26}$ a protein closely related to cell migration and invasion, was detected. As shown in Figures 6 and 7, upon apatinib or raltitrexed treatment for 48 hours, a weaker MMP-9 signal was detected in both cells, and it was further decreased after cells were treated with apatinib and raltitrexed together. Secondly, as PI3K/Akt and Ras/ Erk pathways are the main downstream pathways of VEGF signaling. ${ }^{27,28}$ We examined several essential components of these two pathways. It turned out that apatinib and raltitrexed each down-regulated the phosphorylation of Erk (p-Erk) and Akt (p-Akt) in KYSE-30 and TE-1 cells, and the combinatory treatment further decreased p-Akt and p-Erk level. In contrast, the total protein levels of Erk and Akt in different treating groups remained similar to the control (Figures 6 and 7), indicating apatinib and raltitrexed specifically affected phosphorylated of these two proteins. In addition, phosphorylated VEGFR-2 was markedly reduced in apatinib and the combination group compared to the control group in both KYSE-30 and TE-1 cells $(P<0.01)$, while the content of total VEGFR-2 changed indistinctly during the whole treatment process (Figures 6 and 7). However, the protein levels of phosphorylated VEGFR-2 were not decreased after cells were treated with raltitrexed compared to the control, suggesting that raltitrexed did not act on the phosphorylation site of VEGFR-2. Third, autophagy is a process strictly regulated by autophagy-related genes to maintain intracellular homeostasis for excessive upregulation of autophagy level leads to cell death. ${ }^{29}$ To approve apatinib and raltitrexed really affect cellular autophagy level, a specific marker of autophagy, LC3, ${ }^{30}$ was also examined. LC3-II was converted from LC3-I during the early stages of autophagy, and the increase of LC3-II/I was involved in biosynthesis of the autophagosome. As shown in Figures 6 and 7, despite that apatinib and raltitrexed each strongly stimulated LC3 expression in KYSE-30 and TE- 1 cells after treating for 48 hours, LC3 level was not further elevated when combining both chemicals for treatment, implying that apatinib and raltitrexed induce cellular autophagy without combinatory effect. Collectively, these results suggest that apatinib might inhibit human esophageal squamous carcinoma cells progression via inhibiting Akt and Erk pathways, which can be enhanced by raltitrexed administration.

\section{Discussion}

Although enormous efforts have been made in the last decades, the prognosis and overall survival of patients with ESCC have not been improved substantially due to its resistance to chemotherapy as well as its aggressive nature. The unfavorable treatment outcomes necessitate the development of effective therapeutic approaches for patients with ESCC and complicated tumor microenvironments. In recent years, molecular targeted therapy has been shown to be promising in the treatment of human malignant tumors. Unfortunately, few targeted agents were demonstrated to be effective in patients with ESCC.

The inhibitory effects of apatinib have been reported in a number of human cancer types including gastric cancer, advanced melanoma, hepatocellular carcinoma, and metastatic colorectal cancer. ${ }^{7,-31-33}$ However, after a period of administration, drug resistance becomes an inevitable problem. In addition, targeted oral therapy alone cannot achieve an optimal anti-tumor effect in most cases. The chemotherapeutic agent 5-FU is widely used for the treatment of solid cancer due to its broad spectrum of anticancer activity. Unlike 5-FU, raltitrexed rarely induces cardiotoxicity. ${ }^{34,35}$ For cancer patients with fluoropyrimidine-induced cardiotoxicity or a history of cardiac disease, raltitrexed may be a suitable alternative to $5-\mathrm{FU} .{ }^{12}$ In the present report, we characterized the pharmacodynamics of apatinib and raltitrexed in two VEGFR2-positive ESCC lines, KYSE-30 and TE-1, and we revealed significantly 


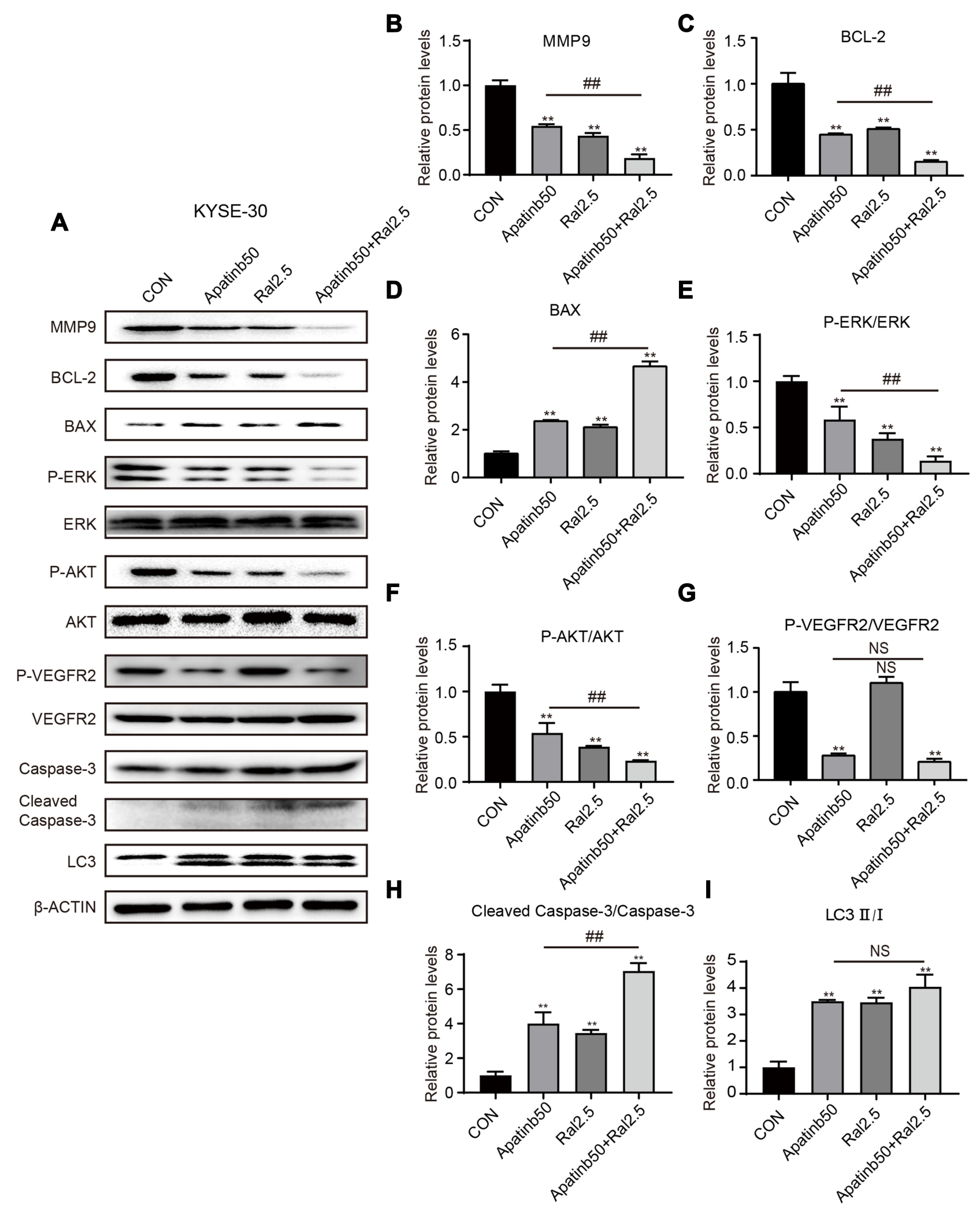

Figure 6 Protein expression after various treatments detected and quantified by Western blot. (A)KYSE-30 cells were treated by $50 \mu$ M apatinib, or $2.5 \mu M$ raltitrexed, or both for 48 hours before expression of MMP-9, BCL-2, BAX, p-ERK, ERK, p-AKT, AKT, p-VEGFR2, VEGFR2, Caspase-3, Cleaved Caspase-3, and LC3 were examined by Western blot analysis. $\beta$-ACTIN was detected as loading control. (B-I) Quantification of different protein expression levels. $* * P<0.01$ (vs control); ${ }^{\# P<0.0 I ~(v s ~} 50 \mu M$ apatinib). 


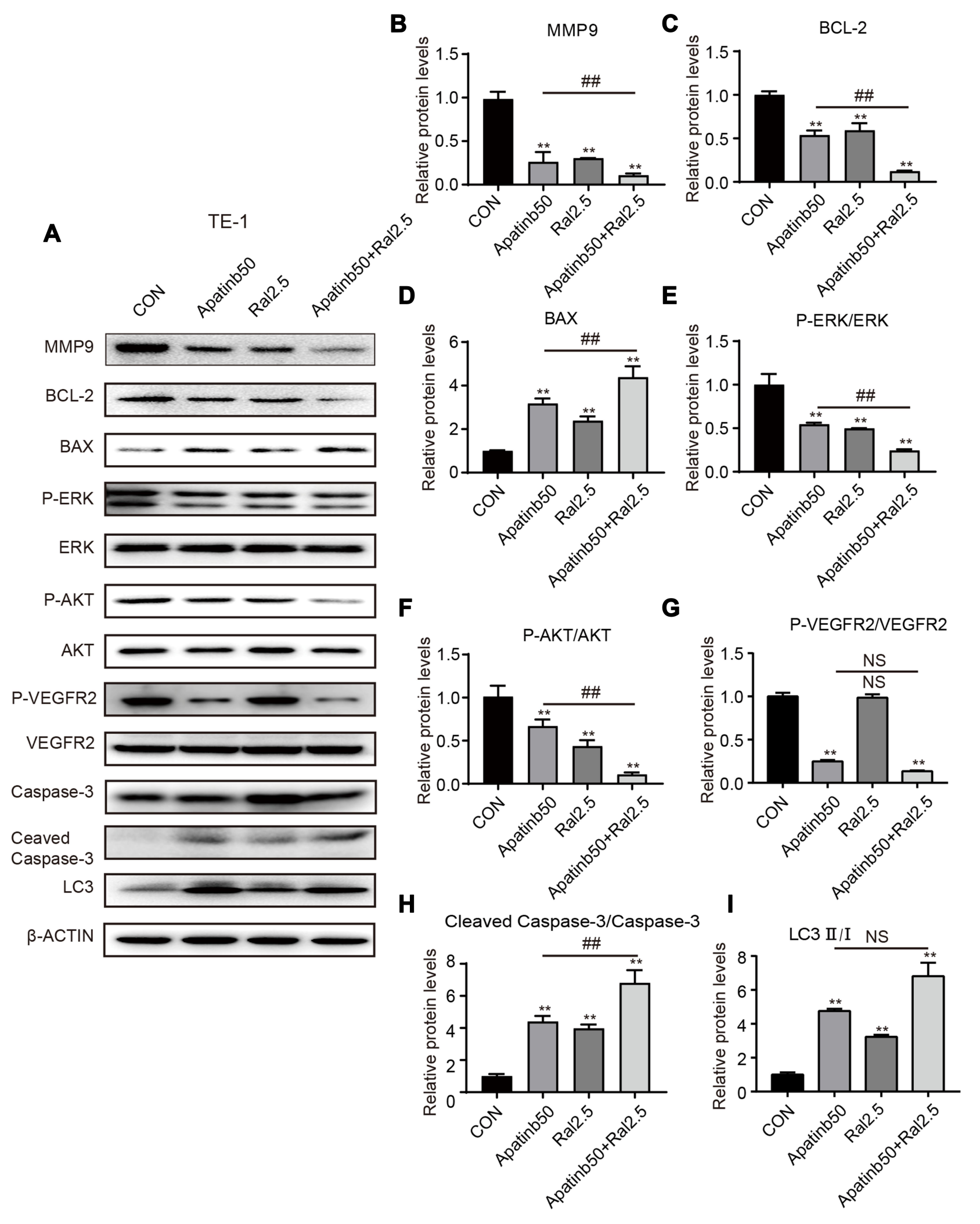

Figure 7 Protein expression after various treatments detected and quantified by Western blot. (A)TE-I cells were treated by $50 \mu M$ apatinib, $2.5 \mu M$ raltitrexed, or both for 48 hours before expression of MMP-9, BCL-2, BAX, p-ERK, ERK, p-AKT, AKT, p-VEGFR2, VEGFR2, Caspase-3, Cleaved Caspase-3, and LC3 were examined by Western blot analysis. $\beta$-ACTIN was detected as loading control. (B-I) Quantification of different protein expression levels. $* * P<0.01$ (vs control); ${ }^{\#} P<0.01$ (vs $50 \mu M$ apatinib). 
enhanced anti-tumor effects after combined administration.

First, our study confirmed the inhibitory effect of raltitrexed and apatinib on cell proliferation by MTS and Colony formation methods, and we also observed that apatinib combined with raltitrexed showed a stronger inhibition on cell migration and invasion (Figures 1-3). Therefore, we think that apatinib combined with raltitrexed is a promising treatment option for ESCC patients in the future. MMP-9 protein is closely related to the invasion and metastasis of tumor cells, and increased MMP-9 protein expression usually indicates poor prognosis. ${ }^{36,37}$ To elucidate why apatinib and raltitrexed have synergetic roles in KYSE-30 and TE-1 cells, the expression level of MMP-9 protein was detected by Western blot analysis. The results showed that apatinib could significantly inhibit the expression of MMP9 in KYSE-30 and TE-1 cells, which would be further inhibited by the administration of raltitrexed (Figures 6 and 7). Based on our findings, we concluded that apatinib inhibited the migration and invasion of cells by inhibiting MMP-9 expression, and the addition of raltitrexed enhanced the inhibitory effects of apatinib on cell invasion.

Second, flow cytometry assay showed that apatinib combined with raltitrexed increased the apoptosis rate of KYSE-30 and TE- 1 cells compared to the apatinib monotherapy group (Figure 4). Consistent with the results of flow cytometry, we observed that the expression of the antiapoptotic protein Bcl-2 mRNA was decreased in apatinib or raltitrexed monotherapy groups and was further inhibited in the apatinib + raltitrexed group (Figure 5). In addition, the expressions of pro-apoptotic protein PARP, Bax, and caspase-3 mRNA were significantly increased in the apatinib and raltitrexed monotherapy groups compared with the control group and further increased in the combination group (Figure 5), and we got similar results in Western blot analysis. These results indicate that apatinib-induced cell apoptosis and raltitrexed could enhance the promoted apoptosis effect of apatinib in KYSE-30 and TE-1 cells.

Third, the expression of two important proteins in the downstream pathway of VEGFR-2, Akt, and Erk plays a vital role in regulating the function of cellular proliferation, invasion, and apoptosis. ${ }^{38,39}$ The disorders of Akt and Erk pathways are closely related to the pathogenesis of numerous human cancers. ${ }^{40}$ Overactivation of $\mathrm{p}$-Akt and p-Erk could prevent cellular apoptosis and stimulate the proliferation and invasion of tumor cells. ${ }^{41}$ To elucidate the underlying mechanisms of the synergistic effect of raltitrexed on apatinib, p-Akt and p-Erk levels were examined by Western blot analysis. The results showed that the expression of p-Akt and p-Erk were inhibited in the apatinib and raltitrexed monotherapy groups and further decreased in the combination therapy group 48 hours after treatment (Figures 6 and 7). Based on our findings, we believe that raltitrexed potentiates the antitumor effects of apatinib on KYSE-30 and TE- 1 cells by blocking Akt and Erk signaling pathways.

The first-line treatment for ESCC is a platinum- or fluorouracil-based agent, followed by later treatment with taxanes or irinotecan. However, there is still no standard third-line treatment for patients with metastatic ESCC during clinical work. Apatinib with concurrent docetaxel has been confirmed to have potential efficacy as a salvage treatment for patients with metastatic ESCC. ${ }^{42}$ A retrospective study was also conducted to evaluate the efficacy of apatinib for advanced ESCC after failed prior first-/further-line treatment, and the values of objective response rate (ORR) and disease control rate (DCR) were $24.2 \%$ and $74.2 \%$, respectively. The median PFS and OS were 115 days and 209 days, respectively. ${ }^{43}$ With the data described above, our study further revealed the enhanced inhibitory effect of raltitrexed and apatinib on ESCC, therefore, itpromises to improve the treatment in the future by administrating them together.

In the current study only in vitro cytology experiments have been performed; the in vivo combinatory effect of apatinib and raltitrexed in animals and human remains to be investigated. Importantly, attention should be paid to the potential side-effects or drug resistance of administrating apatinib and raltitrexed together. Supported by our preliminary results aforementioned, there will be urgent work to do in the near future. More understanding of the molecular mechanisms underlying those combinatory effects may provide better guidance for future clinical applications. For example, as exosome secreted by the cancer cell takes essential roles in carcinoma, determining changes in exosome content after apatinib and raltitrexed treatment may help to understand their activity in ESCC cells. Finally, the combinatory efficacy of apatinib and raltitrexed with other developed target therapy methods for ESCC treatment also need to be studied.

\section{Conclusion}

In the current study, we demonstrated that combinatory treatment of raltitrexed and apatinib in human esophageal squamous carcinoma cells, KYSE-30 and TE-1, produced significant inhibitory effects on cell proliferation, migration, 
and invasion, but induced cell apoptosis by down-regulating the expression of p-Akt, p-Erk, and MMP-9. In addition, we found that both apatinib and raltitrexed application increased cellular autophagy. These results provide a solid theoretical basis for the application of targeted therapy drugs in ESCC, and the combination of apatinib and raltitrexed might be a promising therapeutic option in ESCC. However, due to the lack of clinical evidence for the combinatory application, randomized controlled clinical trials should be studied in the future.

\section{Funding}

This work was supported by Grants from the Research Foundation of Beijing Friendship Hospital, Capital Medical University (No.yyqdkt2017-19); the Digestive Medical Coordinated Development Center of Beijing Hospitals Authority (to Bangwei Cao, No. XXT01); the Beijing key clinical specialist project funding (20182020); the pilot project of clinical collaboration with traditional Chinese medicine and western medicine in major refractory disease-esophageal cancer (to Bangwei Cao, No. 2019-ZX-005).

\section{Disclosure}

The authors report no conflicts of interest in this work.

\section{References}

1. Torre LA, Bray F, Siegel RL, Ferlay J, Lortet-Tieulent J, Jemal A. Global cancer statistics, 2012. CA Cancer J Clin. 2015;65(2):87-108. doi: $10.3322 /$ caac. 21262

2. Yang YS, Hu WP, Ni PZ, Wang WP, Yuan Y, Chen LQ. Esophageal luminal stenosis is an independent prognostic factor in esophageal squamous cell carcinoma. Oncotarget. 2017;8(26):43397-43405. doi:10.18632/oncotarget.14762

3. Lieto E, Ferraraccio F, Orditura M, et al. Expression of vascular endothelial growth factor (VEGF) and epidermal growth factor receptor (EGFR) is an independent prognostic indicator of worse outcome in gastric cancer patients. Ann Surg Oncol. 2008;15(1):69-79. doi:10. 1245/s10434-007-9596-0

4. Hicklin DJ, Ellis LM. Role of the vascular endothelial growth factor pathway in tumor growth and angiogenesis. J Clin Oncol. 2005;23 (5):1011-1027. doi:10.1200/JCO.2005.06.081

5. Luz C, Noguti J, Araújo L, et al. Expression of VEGF and Cox-2 in patients with esophageal squamous cell carcinoma. Asian Pac J Cancer Prev. 2018;19(1):171-177. doi:10.22034/APJCP.2018.19.1. 171

6. Tian S, Quan H, Xie C, et al. YN968D1 is a novel and selective inhibitor of vascular endothelial growth factor receptor-2 tyrosine kinase with potent activity in vitro and in vivo. Cancer Sci. 2011;102(7):1374-1380. doi:10.1111/j.1349-7006.2011.01939.x

7. Li J, Qin S, Xu J, et al. Randomized, double-blind, placebo-controlled phase III trial of apatinib in patients with chemotherapy-refractory advanced or metastatic adenocarcinoma of the stomach or gastroesophageal junction. J Clin Oncol. 2016;34(13):1448-1454. doi:10.1200/ JCO.2015.63.5995
8. Song Z, Yu X, Lou G, Shi X, Zhang Y. Salvage treatment with apatinib for advanced non-small-cell lung cancer. Onco Targets Ther. 2017;10:1821-1825. doi:10.2147/OTT.S113435

9. Hu X, Cao J, Hu W, et al. Multicenter Phase II study of apatinib in non-triple-negative metastatic breast cancer. BMC Cancer. 2014;14:820. doi:10.1186/1471-2407-14-820

10. Li F, Liao Z, Zhao J, et al. Efficacy and safety of Apatinib in stage IV sarcomas: experience of a major sarcoma center in China. Oncotarget. 2017;8(38):64471-64480. doi:10.18632/oncotarget.16 293

11. Jackman AL, Farrugia DC, Gibson W, et al. ZD1694 (Tomudex): a new thymidylate synthase inhibitor with activity in colorectal cancer. Eur J Cancer. 1995;31(7-8):1277-1282. doi:10.1016/09598049(95)00166-g

12. Kelly C, Bhuva N, Harrison M, Buckley A, Saunders M. Use of raltitrexed as an alternative to 5-fluorouracil and capecitabine in cancer patients with cardiac history. Eur J Cancer. 2013;49 (10):2303-2310. doi:10.1016/j.ejca.2013.03.004

13. Planting A, de Jong M, Jansen P, Kerrebijn J, Smith M, Verweij J. Phase I study of concomitant chemoradiation with raltitrexed in locally advanced head and neck cancer. Eur J Cancer. 2005;41 (1):93-97. doi:10.1016/j.ejca.2004.09.022

14. van Meerbeeck JP, Gaafar R, Manegold C, et al. Randomized phase III study of cisplatin with or without raltitrexed in patients with malignant pleural mesothelioma: an intergroup study of the European Organisation for Research and Treatment of Cancer Lung Cancer Group and the National Cancer Institute of Canada. $J$ Clin Oncol. 2005;23(28):6881-6889. doi:10.1200/JCO.20005.14. 589

15. Xue S, Chen YX, Qin SK, et al. Raltitrexed induces mitochondrial-mediated apoptosis in SGC7901 human gastric cancer cells. Mol Med Rep. 2014;10(4):1927-1934. doi:10.3892/mmr.2014.2438

16. Zhao H, Zhang Y, Sun J, Zhan C, Zhao L. Raltitrexed inhibits HepG2 cell proliferation via G0/G1 cell cycle arrest. Oncol Res. 2016;23 (5):237-248. doi:10.3727/096504016X14562725373671

17. Reni M, Pasetto L, Aprile G, et al. Raltitrexed-eloxatin salvage chemotherapy in gemcitabine-resistant metastatic pancreatic cancer. Br J Cancer. 2006;94(6):785-791. doi:10.1038/sj.bjc.6603026

18. Hu L, Sun F, Sun Z, et al. Apatinib enhances the radiosensitivity of the esophageal cancer cell line KYSE-150 by inducing apoptosis and cell cycle redistribution. Oncol Lett. 2019;17(2):1609-1616. doi:10.3892/ol.2018.9803

19. Ding WX, Liu S, Ma JX, et al. Raltitrexed increases radiation sensitivity of esophageal squamous carcinoma cells. Cancer Cell Int. 2019;19:36. doi:10.1186/s12935-019-0752-y

20. Xu WW, Li B, Lam AK, et al. Targeting VEGFR1- and VEGFR2-expressing non-tumor cells is essential for esophageal cancer therapy. Oncotarget. 2015;6(3):1790-1805. doi:10.18632/oncotarget. 2781

21. Li H, Juan L, Xia L, Wang Y, Bao Y, Sun G. Thioridazine sensitizes esophageal carcinoma cell lines to radiotherapy-induced apoptosis in vitro and in vivo. Med Sci Monit. 2016;22:2624-2634. doi:10. 12659/MSM.899950

22. Wu J, Yu J, Wang J, et al. Astragalus polysaccharide enhanced antitumor effects of Apatinib in gastric cancer AGS cells by inhibiting AKT signalling pathway. Biomed Pharmacother. 2018;100: 176-183. doi:10.1016/j.biopha.2018.01.140

23. Wu J, Wang J, Su Q, et al. Traditional Chinese medicine Astragalus polysaccharide enhanced antitumor effects of the angiogenesis inhibitor apatinib in pancreatic cancer cells on proliferation, invasiveness, and apoptosis. Onco Targets Ther. 2018;11:2685-2698. doi:10.2147/ OTT.S157129

24. Ma Y, Yu J, Li Q, Su Q, Cao B. Addition of docosahexaenoic acid synergistically enhances the efficacy of apatinib for triple-negative breast cancer therapy. Biosci Biotechnol Biochem. 2020;84 (4):743-756. doi:10.1080/09168451.2019.1709789 
25. Pan W, Yang J, Wei J, et al. Functional BCL-2 regulatory genetic variants contribute to susceptibility of esophageal squamous cell carcinoma. Sci Rep. 2015;5:11833. doi:10.1038/srep11833

26. Yang L, Song X, Zhu J, et al. Tumor suppressor microRNA-34a inhibits cell migration and invasion by targeting MMP-2/MMP-9/ FNDC3B in esophageal squamous cell carcinoma. Int $J$ Oncol. 2017;51(1):378-388. doi:10.3892/ijo.2017.4015

27. Frezzetti D, Gallo M, Roma C, et al. Vascular endothelial growth factor a regulates the secretion of different angiogenic factors in lung cancer cells. J Cell Physiol. 2016;231(7):1514-1521. doi:10.1002/ jcp. 25243

28. Qiu H, Li J, Liu Q, Tang M, Wang Y. Apatinib, a novel tyrosine kinase inhibitor, suppresses tumor growth in cervical cancer and synergizes with Paclitaxel. Cell Cycle (Georgetown, Tex). 2018;17 (10):1235-1244. doi:10.1080/15384101.2018.1471315

29. Yamazaki T, Kirchmair A, Sato A, et al. Mitochondrial DNA drives abscopal responses to radiation that are inhibited by autophagy. Nat Immunol. 2020;21(10):1160-1171. doi:10.1038/s41590-020-0751-0

30. Wei L, Chen Z, Cheng N, et al. MicroRNA-126 inhibit viability of colorectal cancer cell by repressing mTOR induced apoptosis and autophagy. Onco Targets Ther. 2020;13:2459-2468. doi:10.2147/ OTT.S238348

31. Yang L, Zhu H, Luo P, Chen S, Xu Y, Wang C. Apatinib mesylate tablet in the treatment of advanced malignant melanoma. Onco Targets Ther. 2018;11:5333-5338. doi:10.2147/OTT.S175507

32. Yu WC, Zhang KZ, Chen SG, Liu WF. Efficacy and safety of apatinib in patients with intermediate/advanced hepatocellular carcinoma: a prospective observation study. Medicine (Baltimore). 2018;97(3):e9704. doi:10.1097/MD.0000000000009704

33. Gou M, Si H, Zhang Y, et al. Efficacy and safety of apatinib in patients with previously treated metastatic colorectal cancer: a real-world retrospective study. Sci Rep. 2018;8(1):4602. doi:10. 1038/s41598-018-22302-z

34. Kosmas C, Kallistratos MS, Kopterides P, et al. Cardiotoxicity of fluoropyrimidines in different schedules of administration: a prospective study. J Cancer Res Clin Oncol. 2008;134(1):75-82. doi:10.1007/s00432-007-0250-9
35. Saif MW, Shah MM, Shah AR. Fluoropyrimidine-associated cardiotoxicity: revisited. Expert Opin Drug Saf. 2009;8(2):191-202. doi:10.1517/14740330902733961

36. Candido S, Abrams SL, Steelman LS, et al. Roles of NGAL and MMP-9 in the tumor microenvironment and sensitivity to targeted therapy. Biochim Biophys Acta. 2016;1863(3):438-448. doi:10.1016/ j.bbamcr.2015.08.010

37. Barillari G. The impact of matrix metalloproteinase- 9 on the sequential steps of the metastatic process. Int J Mol Sci. 2020;21(12):4526. doi:10.3390/ijms21124526

38. Ewald F, Nörz D, Grottke A, et al. Vertical targeting of AKT and mTOR as well as dual targeting of AKT and MEK signaling is synergistic in hepatocellular carcinoma. J Cancer. 2015;6(12):11 95-1205. doi:10.7150/jca.12452

39. Adlung L, Kar S, Wagner MC, et al. Protein abundance of AKT and ERK pathway components governs cell type-specific regulation of proliferation. Mol Syst Biol. 2017;13(1):904. doi:10.15252/msb.2016 7258

40. Asati V, Mahapatra DK, Bharti SK. PI3K/Akt/mTOR and Ras/Raf/ MEK/ERK signaling pathways inhibitors as anticancer agents: structural and pharmacological perspectives. Eur J Med Chem. 2016;109:314-341. doi:10.1016/j.ejmech.2016.01.012

41. McCubrey JA, Steelman LS, Chappell WH, et al. Roles of the Raf/ $\mathrm{MEK} / \mathrm{ERK}$ pathway in cell growth, malignant transformation and drug resistance. Biochim Biophys Acta. 2007;1773(8):1263-1284. doi:10.1016/j.bbamcr.2006.10.001

42. Liang LJ, Wen YX, Xia YY, Wang L, Fei JY, Jiang XD. Apatinib combined with docetaxel as a salvage treatment for metastatic esophageal squamous cancer: a case report. Onco Targets Ther. 2018;11:5821-5826. doi:10.2147/OTT.S174429

43. Li J, Wang L. Efficacy and safety of apatinib treatment for advanced esophageal squamous cell carcinoma. Onco Targets Ther. 2017; 10:3965-3969. doi:10.2147/OTT.S132756
OncoTargets and Therapy

\section{Publish your work in this journal}

OncoTargets and Therapy is an international, peer-reviewed, open access journal focusing on the pathological basis of all cancers, potential targets for therapy and treatment protocols employed to improve the management of cancer patients. The journal also focuses on the impact of management programs and new therapeutic

Submit your manuscript here: https://www.dovepress.com/oncotargets-and-therapy-journa agents and protocols on patient perspectives such as quality of life, adherence and satisfaction. The manuscript management system is completely online and includes a very quick and fair peer-review system, which is all easy to use. Visit http://www.dovepress.com/ testimonials.php to read real quotes from published authors. 